\title{
PERCEPÇÃO DOS GESTORES EM RELAÇÃO AO PRINCÍPIO DA CONTROLABILIDADE PARA O ALCANCE DA JUSTIÇA ORGANIZACIONAL
}

\author{
Ilse Maria Beuren \\ ilse.beuren@gmail.com \\ Universidade Federal de Santa Catarina - Florianópolis, SC / Brasil \\ Hugo Dias Amaro \\ hugodamaro@yahoo.com.br \\ Pontifícia Universidade Católica do Paraná - Curitiba, PR \\ Pedro Ylunga Costa da Silva \\ pedroylunga@yahoo.com.br \\ PricewaterhouseCoopers - Luanda, LD / Angola
}

http://dx.doi.org/10.1590/1413-2311.0502014.53640

Recebido em 30/09/2014

Aprovado em 06/07/2015

Disponibilizado em 01/08/2015

Avaliado pelo sistema "double blind review"

Revista Eletrônica de Administração

Editor: Luís Felipe Nascimento

ISSN 1413-2311 (versão "on line")

Editada pela Escola de Administração da Universidade Federal do Rio Grande do Sul.

Periodicidade: Quadrimestral

Sistema requerido: Adobe Acrobat Reader.

\section{RESUMO}

O princípio da controlabilidade propõe que os gestores somente devem ser avaliados com base em elementos controláveis, no pressuposto de que a neutralização dos itens incontroláveis na avaliação de desempenho leva a uma maior satisfação, por ocasionar uma avaliação mais justa. Assim, este estudo objetiva averiguar a percepção dos gestores em relação ao princípio da controlabilidade para o alcance da justiça organizacional. Para tal, pesquisa descritiva com abordagem quantitativa foi realizada a partir de um levantamento junto as 150 Melhores Empresas para Você Trabalhar, conforme a revista Você S/A, de 2011, em que se obteve uma amostra de 63 respondentes. De modo geral, as análises do estudo mostram que o efeito da aplicação do princípio da controlabilidade sobre o desempenho dos gestores nas empresas pesquisadas não é direta e que não leva a um aumento da percepção de justiça organizacional. Os resultados da pesquisa mostram que das hipóteses testadas somente há relação entre o princípio da controlabilidade e a justiça processual. Conclui-se que entre os gestores pesquisados parece não haver uma preocupação com a neutralização dos fatores incontroláveis, o que indica a necessidade de mais pesquisas no que diz respeito à aplicação do princípio da controlabilidade na avaliação de desempenho dos gestores.

Palavras-chave: Percepção dos gestores; Princípio da controlabilidade; Justiça organizacional; Avaliação de desempenho. 
Ilse Maria Beuren, Hugo Dias Amaro \& Pedro Ylunga Costa da Silva

\author{
PERCEPTION OF MANAGERS REGARDING THE PRINCIPLE OF \\ CONTROLLABILITY FOR THE ACHIEVEMENT OF ORGANIZATIONAL \\ JUSTICE
}

\begin{abstract}
The principle of controllability proposes that managers should only be assessed based on the controllable elements, assuming that the neutralization of uncontrollable items in the performance evaluation leads to greater satisfaction, by enabling a fairer assessment. Thus, the goal of this study is to investigate the perception of managers regarding the principle of controllability to the achievement of organizational justice. To this end, descriptive research with quantitative approach was conducted through a survey to the 150 Best Companies to Work For, according to the magazine Você S/A, 2011, in which obtaining a sample of 63 respondents. Overall, the analyzes of the study show that the effect of applying the principle of controllability on the performance of managers in the surveyed companies is not direct and does not lead to an increase in perceived organizational justice. The research results show that of the tested hypothesis there is a relationship only between the principle of controllability and the procedural justice. It is concluded that among the surveyed managers there seems not to be a concern with the neutralization of uncontrollable factors, which indicates the need for more research regarding the application of the principle of controllability in the performance evaluation of managers.
\end{abstract}

Keywords: Perception of managers; Principle of controllability; Organizational justice; Performance evaluation.

\title{
PERCEPCIÓN DE LOS GESTORES EN RELACIÓN CON EL PRINCÍPIO DE CONTROLABILIDAD PARA LOGRAR JUSTICIA ORGANIZACIONAL
}

\begin{abstract}
RESUMEN
El princípio de controlabilidad propone que los gestores sólo deben ser evaluados sobre la base de elementos controlables, en el supuesto de que la neutralización de elementos incontrolables en la evaluación del desempeño conduce a mayor satisfacción, al causar una evaluación más justa. Por lo tanto, este estudio tiene como objetivo investigar la percepción de los gestores en relación con el princípio de controlabilidad para el logro de la justicia organizacional. Para este fin, la investigación descriptiva con enfoque cuantitativo se llevó a cabo a través de una encuesta de las 150 Mejores Empresas para Trabajar, según la revista Você S/A, que 2011, en la que se obtuvo una muestra de 63 encuestados. En general, los análisis del estudio muestran que el efecto de la aplicación del princípio de controlabilidad sobre la actuación de los gestores de las empresas encuestadas no es directo y no conduce a un aumento de la percepción de justicia organizacional. Los resultados de la encuesta muestran que en las hipótesis probadas sólo hay relación entre el princípio de la controlabilidad y la justicia procesal. Llegamos a la conclusión de que entre los gestores encuestados parece que no hay preocupación por la neutralización de factores incontrolables, lo que indica la necesidad de realizar más investigaciones sobre la aplicación del princípio de la controlabilidad en la evaluación del desempeño de los gestores.
\end{abstract}




\section{PERCEPÇÃO DOS GESTORES EM RELAÇÃO AO PRINCÍPIO DA CONTROLABILIDADE PARA O ALCANCE DA JUSTIÇA ORGANIZACIONAL}

Palabras clave: Percepción de los gestores; Princípio de la controlabilidad; Justicia organizacional; Evaluación del desempeño.

\section{INTRODUÇÃO}

O princípio da controlabilidade é comumente citado na literatura para orientar a concepção e o entendimento de sistemas de controle gerencial. O princípio prevê que os gestores só devem ser avaliados com base em elementos que podem controlar. Isso implica na neutralização dos elementos incontroláveis em sua avaliação de desempenho (GIRAUD; LANGEVIN; MENDOZA, 2008; BURKERT; FISCHER; SCHAFFER, 2011). A principal argumentação é que, quando os gestores tem seu desempenho avaliado por fatores que não controlam, entendem a avaliação como injusta e tornam-se insatisfeitos e desmotivados (GIRAUD; LANGEVIN; MENDOZA, 2008; BURKERT; FISCHER; SCHAFFER, 2011).

A aplicação do princípio da controlabilidade interessa tanto à organização como aos gestores avaliados. Para a organização, o princípio serve como importante instrumento na busca de uma entidade cada vez mais justa, principalmente, na avaliação de desempenho dos seus gestores, como também na otimização do sistema de controle gerencial. Aos gestores, é uma forma de garantir para que sejam avaliados por aqueles elementos que são de sua responsabilidade. Isto está condizente com a prática da contabilidade gerencial que busca evitar que os gestores sejam responsabilizados por resultados que vão além do seu controle. No entanto, estudos empíricos apontam que poucas são as empresas que aplicam na íntegra o princípio da controlabilidade (BURKERT; FISCHER; SCHAFFER, 2011).

Do ponto de vista dos gestores avaliados, a busca pela justiça e satisfação tende a leválos a desejar a aplicação da controlabilidade. No entanto, alguns pontos controversos podem ser encontrados, a exemplo da Teoria da Agência, cujo pressuposto é que os gestores são motivados a maximizar suas utilidades, que podem diferir das utilidades dos proprietários. Outro ponto é que alguns fatores incontroláveis podem afetar tanto positiva quanto negativamente o desempenho gerencial, sendo que nessa conjectura o gestor pode contar com a sorte de se beneficiar ou não. Portanto, a posição dos gestores em relação ao princípio da controlabilidade requer mais investigações, uma vez que são percebidas lacunas na literatura.

Assmar, Ferreira e Souto (2005) apontam a justiça como questão central do princípio da controlabilidade, cujo estudo baseia-se na Teoria da Justiça Organizacional. A Justiça Organizacional diz respeito a percepção de justiça pelos funcionários no que se refere às relações de trabalho na organização. Essa temática há muito vem sendo discutida nas organizações preocupadas com o bem-estar dos seus empregados, bem como, por REAd | Porto Alegre - Edição 81 - N 2 - maio/agosto 2015 - p. 378-405 
pesquisadores de diversas áreas, como a Psicologia, Sociologia, Administração, Economia, entre outras ligadas ao comportamento do homem enquanto agente social e econômico (PARKER; KOHLMEYER, 2005). Assmar, Ferreira e Souto (2005) mencionam que a Justiça Organizacional originou-se de estudos desenvolvidos na Psicologia Social, na década de 60.

No entanto, sob a denominação de justiça organizacional, criada por Jerald Greenberg, estudos sobre a justiça no contexto empresarial e de trabalho somente iniciaram em 1987, com o objetivo de investigar as concepções, percepções e reações à justiça ou injustiça por parte dos empregados em relação às organizações em que trabalham (ASSMAR; FERREIRA; SOUTO, 2005). A percepção de justiça organizacional refere-se ao entendimento dos indivíduos sobre o que é justo ou injusto no seu trabalho e influencia no compromisso organizacional e desempenho das pessoas (SOTOMAYOR, 2007).

Denota-se que há uma lacuna de pesquisa, a verificação se a justiça organizacional é o motivo predominante que impulsiona a opinião dos gestores em relação ao princípio da controlabilidade. Embora não se pretenda testar a Teoria da Justiça Organizacional em si, ela pode contribuir para a compreensão da opinião dos gestores sobre o princípio da controlabilidade. Diante dos argumentos expostos tem-se a questão de pesquisa norteadora do estudo: Qual a percepção dos gestores em relação ao princípio da controlabilidade para o alcance da justiça organizacional? Assim, o objetivo é averiguar a percepção dos gestores em relação ao princípio da controlabilidade para o alcance da justiça organizacional.

A relevância do estudo está em se trazer evidências empíricas adicionais para o entendimento da opinião dos gestores quanto ao princípio da controlabilidade, além de mostrar o quanto esse princípio pode ser uma via de acesso para o alcance da justiça nas organizações. O estudo avança em relação à pesquisa realizada por Giraud, Langevin e Mendoza (2008), que analisaram a opinião dos gestores sobre a relevância do processo de neutralização, considerando três tipos de fatores incontroláveis. No presente estudo inclui-se na avaliação do esquema teórico do processo de neutralização uma aplicação multivariada, denominada Análise de Equações Estruturais, estimada a partir dos Mínimos Quadrados Parciais (Partial Least Squares - PLS), no intuito de identificar a relação dos três fatores incontroláveis com a percepção de justiça organizacional.

Seguindo a linha de Giraud, Langevin e Mendonza (2008), o estudo faz associação entre a justiça organizacional e o princípio da controlabilidade, pois ambos estão ligados de forma intrínseca na avaliação de desempenho dos gestores. A Teoria da Justiça Organizacional fornece um quadro interessante para analisar a percepção de justiça na 
PERCEPÇÃO DOS GESTORES EM RELAÇÃO AO PRINCÍPIO DA

CONTROLABILIDADE PARA O ALCANCE DA JUSTIÇA ORGANIZACIONAL

avaliação de desempenho e da controlabilidade (GREENBERG, 1990). A principal motivação para a pesquisa é contribuir para o arcabouço teórico e prático sobre o princípio da controlabilidade no âmbito das organizações brasileiras.

$\mathrm{O}$ estudo justifica-se nas perspectivas teórica e prática. Na perspectiva teórica justifica-se à medida que procura contribuir para o desenvolvimento do quadro teórico relativo ao tema da pesquisa, uma vez que poucas são as pesquisas verificadas na literatura nacional. Por outro lado, o tema servirá para um melhor entendimento sobre o processo de avaliação de desempenho utilizado em organizações brasileiras, a partir da opinião dos seus gestores, centrando-se basicamente na aplicação do princípio da controlabilidade sobre a percepção da justiça organizacional.

\section{REVISÃO BIBLIOGRÁFICA}

\subsection{Princípio da controlabilidade}

A aplicação do princípio da controlabilidade é relevante sob o ponto de vista da motivação dos gestores (HUFFMAN; CAIN, 2000), pois contribui para adequar os esforços do trabalho gerencial e contornar comportamentos disfuncionais (BURKERT; FISCHER; SCHAFFER, 2011). A motivação é um dos efeitos da aplicação desse princípio, pois motiva os gestores mais qualificados a participar, permanecer, aumentar ou melhorar a alocação dos seus esforços na empresa (BURKERT; FISCHER; SCHAFFER, 2011).

O princípio da controlabilidade rege que os gestores devem ser avaliados com base no que eles podem controlar. Se fatores incontroláveis, como mudanças imprevistas no ambiente ou decisões tomadas por outros, afetam os resultados dos gestores, o princípio da controlabilidade estabelece que esses fatores devem ser neutralizados (GIRAUD; LANGEVIN; MENDOZA, 2008). Este processo de neutralização pode assumir duas formas: ex ante e ex post. A neutralização ex ante consiste em selecionar medidas de desempenho que excluam os itens que os gestores não podem controlar. A neutralização ex post consiste em fazer um ajuste no final do ano para remover os impactos dos fatores incontroláveis que afetaram o desempenho dos gestores (MERCHANT; VAN DER STEDE, 2003).

Pesquisas que abordam o princípio da controlabilidade em uma perspectiva teórica enfatizam dois argumentos principais para o interesse das organizações na sua aplicação. Primeiramente, ele fornece uma avaliação confiável do desempenho gerencial. Segundo, ele ajuda as empresas a influenciar o comportamento dos gestores, porque está ligado de forma intrínseca ao de equidade (GIRAUD; LANGEVIN; MENDOZA, 2008). Outro argumento 
encontrado na literatura é o papel do stress como uma indesejável consequência aos gestores quando as empresas não aplicam o princípio da controlabilidade na avaliação de desempenho (FOGARTY et al., 2000). Sua aplicação também faz com que os gestores desperdicem menos tempo em convencer os seus superiores de que o seu desempenho decorre de fatores incontroláveis, em vez de seus esforços (MODELL; LEE, 2001).

Depreende-se que vários são os argumentos teóricos a favor da aplicação do princípio da controlabilidade. Porém, evidências empíricas mostram que nem sempre ele é estritamente implementado na prática. Estudos anteriores, como os de Frow, Marginson e Ogden (2005) e de Burkert, Fischer e Schaffer (2011), têm enfatizado que o desempenho de outros gestores tem afetado significativamente o resultado das ações dos gestores.

Os gestores, por sua vez, esperam obter benefícios financeiros com fatores que não controlam ao final do período, à medida que são realizados ajustes no resultado da empresa, acreditando que estes poderão aumentar a sua avaliação de desempenho e maximizar o resultado da empresa. Porém, tal fato não ocorre, pois os ajustes são realizados de forma parcial, e isso não garante efeito significativo no resultado da empresa (FROW; MARGINSON; OGDEN, 2005; GIRAUD; LANGEVIN; MENDOZA, 2008). De acordo com Manzoni (2002), é pouco provável que o desempenho das empresas seja maximizado concentrando os esforços dos gestores em dimensões e medidas que são controláveis.

Burkert, Fischer e Schaffer (2011) citam que dois argumentos da literatura tentam explicar esses resultados empíricos. Primeiro, destacam que alguns autores têm advertido que não é sempre de pleno interesse da empresa aplicar o princípio da controlabilidade. Por exemplo, os gestores responsáveis por fatores de desempenho que não podem controlar totalmente, mas que podem pelo menos influenciar, serão induzidos a continuar dando atenção para esses fatores influenciáveis, ou seja, no âmbito da teoria do agente e principal, sob certas condições de assimetria de informação, é do seu interesse manipular toda e qualquer informação à sua disposição (GIRAUD; LANGEVIN; MENDOZA, 2008). O segundo argumento decorre das dificuldades inerentes à aplicação do princípio da controlabilidade, pois os fatores incontroláveis nem sempre são fáceis de avaliar (BURKERT; FISCHER; SCHAFFER, 2011).

À luz do aparente paradoxo do princípio da controlabilidade e da sua aparente limitada aplicabilidade, Merchant e Manzoni (1989) e Hartman e Slapnicar (2009) trazem o princípio para níveis elevados de complexidade e de incerteza. A maioria das pesquisas teóricas e empíricas realizadas sobre o princípio da controlabilidade adota um ponto de vista específico, 


\section{PERCEPÇÃO DOS GESTORES EM RELAÇÃO AO PRINCÍPIO DA CONTROLABILIDADE PARA O ALCANCE DA JUSTIÇA ORGANIZACIONAL}

a premissa subjacente é que o princípio é uma condição de justiça, o que leva à satisfação e motivação dos gestores, por sua vez, conduzindo ao desempenho desejado pela organização (GIRAUD; LANGEVIN; MENDOZA, 2008).

Portanto, existe um elo entre o princípio da controlabilidade e da justiça organizacional. A justiça organizacional é fundamental para o adequado funcionamento de sistemas de avaliação de desempenho, enquanto que o princípio da controlabilidade atribui ao sistema de desempenho características de justiça na medida em que o gestor será avaliado apenas pelos fatores controláveis (ANGONESE; BEUREN, 2012). Desta forma, destaca-se aqui a importância que tem a aplicação do princípio da controlabilidade nas organizações, enquanto instrumento gerencial para o alcance da justiça organizacional.

Em prol da aplicação do princípio da controlabilidade no processo de avaliação de desempenho dos gestores identificaram-se algumas pesquisas publicadas em periódicos internacionais, entre elas destacam-se as expostas no Quadro 1.

Quadro 1 - Pesquisas sobre o princípio da controlabilidade publicadas em periódicos internacionais

\begin{tabular}{|c|c|c|}
\hline Autores & Periódico & Temática abordada e Resultados \\
\hline Hirst (1983) & Abacus & $\begin{array}{l}\text { Fornece um quadro para a identificação de situações em que os resultados } \\
\text { são capturados por medidas mais (menos) suscetíveis de serem controláveis. } \\
\text { Os resultados de um inquérito por questionário apoiam a alegação de que no } \\
\text { aumento da incerteza das tarefas, os indivíduos percebem menos controle } \\
\text { sobre os resultados financeiros. }\end{array}$ \\
\hline $\begin{array}{c}\text { Choudhury } \\
\text { (1986) }\end{array}$ & $\begin{array}{l}\text { Accounting } \\
\text { and Business } \\
\text { Research }\end{array}$ & $\begin{array}{l}\text { Analisa o princípio da controlabilidade fundamentado no conceito da } \\
\text { contabilidade por responsabilidade. Com base nas proposições formuladas, } \\
\text { os resultados indicam que a controlabilidade não é um "bom" condicionante } \\
\text { e se a contabilidade por responsabilidade servir ao seu propósito, de } \\
\text { promover os objetivos da empresa, não deve ser restritiva pela } \\
\text { controlabilidade. }\end{array}$ \\
\hline $\begin{array}{l}\text { Antle e } \\
\text { Demski } \\
(1988)\end{array}$ & $\begin{array}{c}\text { The } \\
\text { Accounting } \\
\text { Review }\end{array}$ & $\begin{array}{l}\text { Examina o princípio da controlabilidade no processo de avaliação gerencial } \\
\text { entre o agente-principal e verifica se os procedimentos escolhidos pelas } \\
\text { empresas têm alguma relação lógica com a definição da controlabilidade. Os } \\
\text { resultados demonstraram não existir qualquer relação entre a escolha dos } \\
\text { métodos de avaliação gerencial com o princípio da controlabilidade. }\end{array}$ \\
\hline Shih (1997) & $\begin{array}{c}\text { Social Science } \\
\text { Research } \\
\text { Network }\end{array}$ & $\begin{array}{l}\text { Investiga como as empresas desenham os sistemas de avaliação de } \\
\text { desempenho para os gerentes de fábrica. Os resultados da Teoria da Agência } \\
\text { mostram que o peso colocado sobre uma variável na avaliação de } \\
\text { desempenho depende de sua precisão e das informações que ela contém, não } \\
\text { transmitidas por outras variáveis. Isto sugere uma tendência para avaliar um } \\
\text { gerente de fábrica principalmente sobre o lucro em vez do custo. }\end{array}$ \\
\hline $\begin{array}{l}\text { Ghosh e } \\
\text { Lusch } \\
(2000)\end{array}$ & $\begin{array}{c}\text { Accounting, } \\
\text { Organizations } \\
\text { and Society }\end{array}$ & $\begin{array}{l}\text { Fornece evidências do efeito no resultado das avaliações de desempenho dos } \\
\text { gestores de uma cadeia de varejo. As avaliações subjetivas dos gerentes de } \\
\text { lojas foram feitas pelos seus supervisores, sofrendo impacto negativo devido } \\
\text { ao conhecimento desfavorável dos mesmos. Os resultados demonstraram que } \\
\text { a avaliação dos gestores sofre influência somente dos determinantes do } \\
\text { resultado que estes controlam, deixando de fora os determinantes ambientais } \\
\text { do resultado sobre os quais estes não têm controle nas suas avaliações. Os } \\
\text { determinantes de resultados provenientes das decisões hierárquicas sobre os } \\
\text { quais os gerentes não têm controle também influenciam nas suas avaliações. }\end{array}$ \\
\hline Modell e & Financial & Verifica em que medida e como fatores institucionais incidem sobre a \\
\hline
\end{tabular}

REAd | Porto Alegre - Edição 81 - Nº 2 - maio/agosto 2015 - p. 378-405 


\begin{tabular}{|c|c|c|}
\hline Lee (2001) & $\begin{array}{l}\text { Accountability } \\
\text { Manangement }\end{array}$ & $\begin{array}{l}\text { relação entre descentralização e a confiança sobre o princípio da } \\
\text { controlabilidade no contexto do setor público. Os resultados sugerem que as } \\
\text { práticas de descentralização institucional alocadas ao setor público tendem a } \\
\text { reduzir a confiança sobre o princípio da controlabilidade. }\end{array}$ \\
\hline $\begin{array}{l}\text { Ghosh } \\
(2005)\end{array}$ & $\begin{array}{l}\text { Behavioral } \\
\text { Research in } \\
\text { Accounting }\end{array}$ & $\begin{array}{l}\text { Examina as medidas de desempenho alternativas de avaliação de gestores, } \\
\text { verificando junto ao avaliador se as medidas de avaliação de desempenho } \\
\text { com vários aumentos ou diminuições no efeito da controlabilidade sobre o } \\
\text { resultado, a priori, atenuam o efeito da controlabilidade. Os resultados } \\
\text { experimentais revelam que o aumento do efeito da controlabilidade sobre o } \\
\text { resultado é verificado mais em medidas não-financeiras do que em medidas } \\
\text { financeiras. Mostram ainda que a avaliação da capacidade de controle do } \\
\text { resultado mede, antes da avaliação, o efeito real reduzido em todas as } \\
\text { medidas de desempenho. }\end{array}$ \\
\hline $\begin{array}{l}\text { Giraud, } \\
\text { Langevin e } \\
\text { Mendoza } \\
\text { (2008) }\end{array}$ & $\begin{array}{l}\text { Management } \\
\text { Accounting } \\
\text { Research }\end{array}$ & $\begin{array}{l}\text { Verifica a opinião dos gestores sobre o princípio da controlabilidade no } \\
\text { processo de avaliação de desempenho justo, a partir da neutralização dos três } \\
\text { tipos de fatores incontroláveis. Os } 265 \text { gestores franceses entrevistados } \\
\text { demonstraram uma diferença significativa entre os fatores incontroláveis, } \\
\text { externos à empresa (interdependentes) ou internos (decisões hierárquicas), } \\
\text { oferecendo uma nova visão no que diz respeito à justificativa para o } \\
\text { princípio da controlabilidade. }\end{array}$ \\
\hline $\begin{array}{l}\text { Ocansey e } \\
\text { Enahoro } \\
(2012)\end{array}$ & $\begin{array}{c}\text { Canadian } \\
\text { Social Science }\end{array}$ & $\begin{array}{l}\text { Examina a literatura sobre o princípio de controlabilidade relativa ao } \\
\text { conceito de contabilidade por responsabilidade como determinante do } \\
\text { planejamento do lucro, estabelecendo relações de causa e efeito entre as } \\
\text { atividades específicas dos gestores e o desempenho de suas atividades. Os } \\
\text { resultados demonstram a existência de dois níveis extremos na aplicação do } \\
\text { princípio da controlabilidade: nível baixo e nível alto da aplicação de } \\
\text { sistemas contábeis baseados na controlabilidade. }\end{array}$ \\
\hline
\end{tabular}

Fonte: Elaboração própria com base nos autores referenciados.

Observa-se no Quadro 1, que a aplicação do princípio da controlabilidade não é uma medida de avaliação de desempenho gerencial utilizada de forma completa nas organizações, uma vez que não existe relação entre a escolha dos métodos de avaliação de desempenho utilizados e o princípio da controlabilidade. Este fato pode ser explicado em função da diferença significativa existente entre os fatores incontroláveis, que estão na base do uso do princípio da controlabilidade na sua forma plena.

Em âmbito nacional, as pesquisas em prol do princípio da controlabilidade como medida para avaliação de desempenho dos gestores para o alcance da justiça organizacional ainda é incipiente. Embora existam trabalhos relacionados à determinação das medidas de desempenho dos gestores de empresas brasileiras, mas não realçam o princípio da controlabilidade. Por exemplo, Camargos, Helal e Boas (2007) investigaram a relação entre o desempenho financeiro e a remuneração de executivos de empresas brasileiras de capital aberto com ADRs; Dalmacio, Rezende e Slomski (2009) demonstraram que, em alguns setores específicos, os indicadores de performance podem ser utilizados como parâmetros de remuneração dos gestores. Teixeira, Gonzaga e Santos (2011) evidenciaram que não existe relação entre o nível de risco da empresa e de incentivos gerenciais oferecidos aos gestores. 


\section{PERCEPÇÃO DOS GESTORES EM RELAÇÃO AO PRINCÍPIO DA CONTROLABILIDADE PARA O ALCANCE DA JUSTIÇA ORGANIZACIONAL}

Um único estudo empírico publicado em periódico nacional foi identificado na Revista de Administração de Empresas, desenvolvido por Aguiar et al. (2012), que investigou a existência da relação entre a presença de incentivos gerenciais e as práticas de contabilidade gerencial associada ao princípio da controlabilidade. Os resultados sugerem que apenas o orçamento anual, a análise por centro de responsabilidade e a avaliação de desempenho estão associados à presença de sistemas de incentivos nas empresas em que realizaram entrevistas.

Ao contrário do que se observa nas pesquisas em âmbito internacional, o interesse sobre o princípio da controlabilidade no Brasil é recente. Isso coloca em evidência possíveis discussões sobre o assunto nos contextos empresarial e acadêmico brasileiro, ao mesmo tempo em que abre um campo de pesquisa interessante na área da contabilidade sob a perspectiva comportamental.

\subsection{Justiça organizacional}

O tema justiça organizacional surgiu por volta da década de 1960, a partir de estudos desenvolvidos na área da Psicologia Social (ASSMAR; FERREIRA; SOUTO, 2005; SOTOMAYOR, 2007). Estudos segmentados no contexto empresarial iniciaram-se com o trabalho de Greenberg (1987), que investigou as concepções e percepções no que concerne ao sentimento de justiça e injustiça por parte dos empregados em relação às organizações em que trabalham (ASSMAR; FERREIRA; SOUTO, 2005).

Greenberg (1987) define justiça organizacional como sendo os esforços para tentar explicar os efeitos da justiça no funcionamento das organizações. Folger e Cropanzano (1998) conceituam a justiça organizacional como a condição individual do funcionário de acreditar que está sendo tratado de forma justa ou injusta pela sua organização. Baldwin (2006) referese à ela como sendo a extensão com que é percebida como justa pelos funcionários a interação nos procedimentos utilizados na avaliação de seu trabalho.

A justiça organizacional é um importante motivador para o trabalho (ASSMAR; FERREIRA; SOUTO, 2005). Os autores relatam, quando percebida pelos funcionários a injustiça no trabalho, a moral destes declina imediatamente, podendo haver retaliações, tais como: aumento de pedidos de demissões, elevado número de fraudes e roubos, descaso com a empresa, entre outros comportamentos. Estudos na Psicologia e na Administração já demonstraram a importância da justiça organizacional para auxiliar os gestores na compreensão dos diferentes comportamentos e atitudes dos indivíduos nas organizações, a partir das diferentes percepções que a mesma pode ser abordada (PEREIRA, 2008). 
Ilse Maria Beuren, Hugo Dias Amaro \& Pedro Ylunga Costa da Silva

Embora o tema justiça organizacional tenha surgido por volta da década de 1960, os estudos no enfoque organizacional são recentes. De modo geral, as percepções de justiça organizacional afetam uma gama de atitudes e comportamentos organizacionais que podem interagir entre si na busca de uma explicação (LIBBY, 1999; COLQUITT et al. 2001; JAWAHAR, 2002; REGO; SOUTO, 2004; FILENGA; SIQUEIRA, 2006; SOTOMAYOR, 2007; BURNEY; HENLE; WIDENER, 2009; SOUSA; MENDONÇA, 2009; ZAINALIPOUR; FINI; MIRKAMALI, 2010; NADIRI; TANOVA, 2010; SEIFERT et al., 2010; BEUREN; SANTOS, 2012; LANGEVIN; MENDOZA, 2013). Entre os trabalhos desenvolvidos em prol da justiça organizacional na área organizacional, nenhum deles relacionou o papel da controlabilidade na justiça organizacional.

A justiça organizacional possui diversas percepções, as quais podem ser analisadas em diferentes contextos como argumentado por Beuren e Santos (2012), que vão desde a política salarial utilizada até a medida de avaliação de desempenho escolhida. Também não há consenso por parte dos pesquisadores quanto às dimensões da justiça organizacional. Há os que utilizam duas dimensões, a distributiva e a processual ou procedimental, como Greeenberg (1987), Konovsky e Cropanzano (1991). Há autores que utilizam um terceiro julgamento, a dimensão interacional, como Bies e Moag (1986), Bies e Shapiro (1987). E ainda há autores que utilizam quatro dimensões e segregam a justiça interacional em duas, a interpessoal e a informacional, como Greenberg (1993), Colquitt et al. (2001), Rego e Souto (2004), Assmar, Ferreira e Souto (2005), Sotomayor (2006, 2007), Langevin e Mendoza (2013).

No entanto, há unanimidade entre os pesquisadores na consideração de que as dimensões de justiça distributiva e justiça processual são variáveis latentes independentes, apesar de estarem correlacionadas entre si (SANTOS; BEUREN, 2012). A justiça distributiva analisa as percepções de justiça dos empregados no que tange à algumas formas de gratificação, tais como: promoções, aumentos nos salários, premiações de fim de ano e participação em programas de formação (SOTOMAYOR, 2007).

Para Rego e Souto (2002, p. 215), a justiça distributiva "foi a que primeiro suscitou a atenção dos cientistas organizacionais. Focaliza-se no conteúdo, isto é, na justiça dos fins alcançados ou obtidos". Essa determinação de recebimento de recompensas representa uma questão de justiça importante, devendo a decisão ser consistente e sem qualquer viés ou dúvida entre os indivíduos (PEREIRA, 2008).

Nesta linha, Babcock et al. (1995) argumentam que, para ser considerado justo REAd | Porto Alegre - Edição 81 - N 2 - maio/agosto 2015 - p. 378-405 


\section{PERCEPÇÃO DOS GESTORES EM RELAÇÃO AO PRINCÍPIO DA CONTROLABILIDADE PARA O ALCANCE DA JUSTIÇA ORGANIZACIONAL}

dependerá da alocação em favor das próprias pessoas sem qualquer viés. Parker e Kohlmeyer (2005) afirmam que quando os funcionários percebem que a empresa é tendenciosa, podem ocorrer reações negativas, por exemplo, pode haver menor comprometimento organizacional, menor satisfação no trabalho, e aumento na rotação de funcionários.

No que compete à justiça procedimental ou processual, a ênfase incide na justiça dos processos e procedimentos adotados na distribuição de recompensas. O foco é a justiça dos meios de resolução dos conflitos ou dos processos de tomada de decisão em relação à repartição de recursos entre os membros envolvidos (ASSMAR; FERREIRA; SOUTO, 2005). Normalmente, a regra utilizada para estabelecer as comparações entre indivíduos é o princípio da equidade, ou seja, reconhecer imparcialmente o direito de cada um (SOTOMAYOR, 2007). Folger e Cropanzano (1998, p. 26) resgatam que a justiça processual "refere-se às questões de justiça relativas aos métodos, mecanismos e processos utilizados para determinar os outcomes". Os autores destacam ainda que "estas questões podem envolver considerações acerca do modo adequado para conduzir um processo de tomada de decisão, um processo de resolução de conflitos ou um processo de afetação numa organização".

A justiça interacional "reflete a qualidade da interação com as decisões" (REGO; SOUTO, 2004, p. 156). Ela analisa as percepções de justiça relativas ao tratamento interpessoal que os indivíduos recebem quando os procedimentos são implementados (SOTOMAYOR, 2006). Bies e Moag (1986) defendem que há diferenças conceituais entre as dimensões de justiça processual e interacional, a primeira está relacionada aos procedimentos formais do processo decisório, já a segunda faz a análise da qualidade da interação no seu decurso. Além disso, que essas duas dimensões são independentes da justiça distributiva.

Segundo Greenberg (1993), a justiça interacional é dividida em interpessoal e informativa. A justiça interpessoal verifica se as pessoas são tratadas com respeito e dignidade e a justiça informativa focaliza-se nas justificativas prestadas às pessoas. Assim, a justiça interpessoal "reflete o grau segundo o qual as pessoas são tratadas com cortesia, dignidade e respeito pelas autoridades ou pelas terceiras partes envolvidas na execução de procedimentos ou na determinação de outcomes" (COLQUITT et al., 2001, p. 427). E a justiça informacional focaliza-se "nas explicações fornecidas às pessoas interessadas na informação sobre o porquê de certos procedimentos terem sido utilizados de determinado modo ou o porquê dos outcomes terem sidos distribuídos daquela maneira" (COLQUITT et al., 2001, p. 427).

Desse modo, o alcance da justiça nas organizações não é tarefa fácil para as empresas, pois envolve um conjunto de fatores internos e externos, que estão ligados ao processo de 
avaliação de desempenho e às regras de distribuição de benefícios entre os empregados. Adicionalmente, depreende-se do exposto sua possível conectividade com a aplicação do princípio da controlabilidade na avaliação de desempenho dos gestores nas organizações. Com o intuito de investigar o imbricamento entre esses dois conceitos na avaliação de desempenho de gestores em organizações, expõe-se a seguir o estudo de Giraud, Langevin e Mendoza (2008), que operacionalizaram a aplicação do princípio da controlabilidade.

\subsection{Estudo de Giraud, Langevin e Mendoza (2008)}

O estudo de Giraud, Langevin e Mendoza (2008) fundamenta a presente pesquisa, por isso é sintetizado em um tópico específico. Assim, como justificativa para o estudo, esses autores ressaltam que os primeiros estudos sobre a aplicação do princípio da controlabilidade já citavam os fatores incontroláveis que impactam na avaliação dos gestores nas organizações. Merchant (1989) efetuou um estudo empírico observando as diferenças na aplicação do princípio da controlabilidade de acordo com os diversos tipos de fatores incontroláveis, e constatou que as empresas ajustam muito mais fatores internos do que fatores externos.

Merchant (1989) entrevistou gestores de centros de lucro para explorar a prática da empresa e as reações dos gestores em relação às práticas utilizadas. Constatou que os gestores de centros de lucro têm sentimentos mistos em relação ao princípio da controlabilidade, sendo que alguns foram favoráveis a sua aplicação na empresa e outros não. $\mathrm{O}$ autor verificou ainda que os benefícios potenciais de ajuste dos fatores incontroláveis aumentam com o tamanho dos efeitos de distorção dos fatores incontroláveis. Portanto, quanto mais forem incontroláveis os fatores, maior será o efeito destes sobre o desempenho dos gestores, o que resulta no aumento do desejo dos gestores para a sua neutralização.

Dessa forma, baseados nas argumentações de Merchant (1989), Giraud, Langevin e Mendoza (2008) objetivaram em seu estudo trazer novas evidências empíricas e tentar entender melhor a opinião dos gestores quanto ao princípio da controlabilidade. A população inicial da pesquisa foi de 1.156 gerentes de um banco de dados de ex-alunos de uma instituição de ensino superior francesa. Entre esses, investigaram apenas os gerentes funcionais, isto é, excluíram os gerentes de função de apoio porque seu desempenho é difícil de definir e medir. Assim, de uma população de 1.099 gerentes obtiveram 265 respostas, representando uma amostra de $24 \%$.

A formulação das hipóteses foi pautada nos estudos sobre a aplicação do princípio da controlabilidade de Demski (1976), Choudhury (1986), Merchant (1989), Merchant e Van 


\section{PERCEPÇÃO DOS GESTORES EM RELAÇÃO AO PRINCÍPIO DA CONTROLABILIDADE PARA O ALCANCE DA JUSTIÇA ORGANIZACIONAL}

Der Stede (2003). As variáveis consideradas no estudo foram três fatores incontroláveis: interdependências horizontais - decisões tomadas por outros gestores da empresa; interdependências verticais/hierarquias - decisões tomadas por superiores; e fatores externos mudanças imprevistas ocorridas na economia, competitividade de mercados e outros fenômenos naturais ocorridos no meio ambiente, como catástrofes naturais e outros.

O questionário do estudo de Giraud, Langevin e Mendoza (2008) foi composto por 40 questões, incluindo as questões descritivas e abertas. Para sua validação, foi submetido a um pré-teste com oito gerentes, antes de ser enviado à população da pesquisa, momento em que foi possível esclarecer aquelas perguntas que geraram dúvidas. Ressalte-se que o instrumento de pesquisa não foi anexado ao artigo publicado.

Os resultados da pesquisa revelaram que os gestores são pouco favoráveis à neutralização total de fatores internos incontroláveis, mas apresentaram opiniões diferentes dependendo dos fatores internos incontroláveis apontados no instrumento de pesquisa. Entretanto, no que se refere aos fatores ou eventos externos, os gestores preferiram a não aplicação do princípio da controlabilidade, por temerem que um nível elevado de dificuldade de neutralizar o seu efeito poderá resultar em subjetividade na avaliação de desempenho e assim resultar em injustiça organizacional.

\section{PROCEDIMENTOS METODOLÓGICOS}

O estudo utiliza-se da abordagem metodológica empírico-positiva, que estuda os fatos buscando estabelecer relações entre as variáveis de estudo mediante o controle e sistematização de dados empíricos, explicando e descrevendo os fenômenos observados (MARTINS; THEÓPHILO, 2009).

A pesquisa caracteriza-se como descritiva quanto aos seus objetivos, conforme preceitua Gil (2002). Apresenta características de pesquisa quantitativa quanto à abordagem do problema e natureza das variáveis, segundo propõe Demo (1989). E utiliza-se da técnica de levantamento de dados, numa dimensão seccional, para a coleta dos dados.

\subsection{Hipóteses da pesquisa}

Giraud, Langevin e Mendoza (2008) consideraram em sua pesquisa três fatores incontroláveis, que resultaram, respectivamente, em três hipóteses de pesquisa. No presente estudo, a cada uma dessas hipóteses foram adicionadas as percepções de justiça organizacional, de acordo com a proposta desse estudo: 
H1. A extensão em que o desempenho dos gestores é afetado por decisões tomadas por gestores do mesmo nível hierárquico está positivamente relacionada ao desejo dos gestores de que os efeitos dessas decisões sejam neutralizados em sua avaliação de desempenho, aumentando a percepção da justiça distributiva (H1a), justiça processual (H1b), justiça interacional (H1c) e justiça informacional (H1d).

H2. A extensão em que o desempenho dos gestores é afetado pelas decisões tomadas por seus superiores hierárquicos está positivamente relacionada ao desejo dos gestores de que os efeitos dessas decisões sejam neutralizados em sua avaliação de desempenho, aumentando a percepção da justiça distributiva (H2a), justiça processual (H2b), justiça interacional (H2c) e justiça informacional (H2d).

H3. A extensão em que o desempenho dos gestores é afetado por fatores externos incontroláveis está positivamente relacionada ao desejo dos gestores de que os efeitos de tais fatores sejam neutralizados em sua avaliação de desempenho, aumentando a percepção da justiça distributiva (H3a), justiça processual (H3b), justiça interacional (H3c) e justiça informacional (H3d).

As hipóteses formuladas pretendem testar quais são os fatores que afetam a avaliação de desempenho dos gestores, tendo a implementação do princípio da controlabilidade como mecanismo de neutralização, e levam a uma maior percepção de justiça organizacional. Assim, segue na Figura 1 o modelo conceitual proposto.

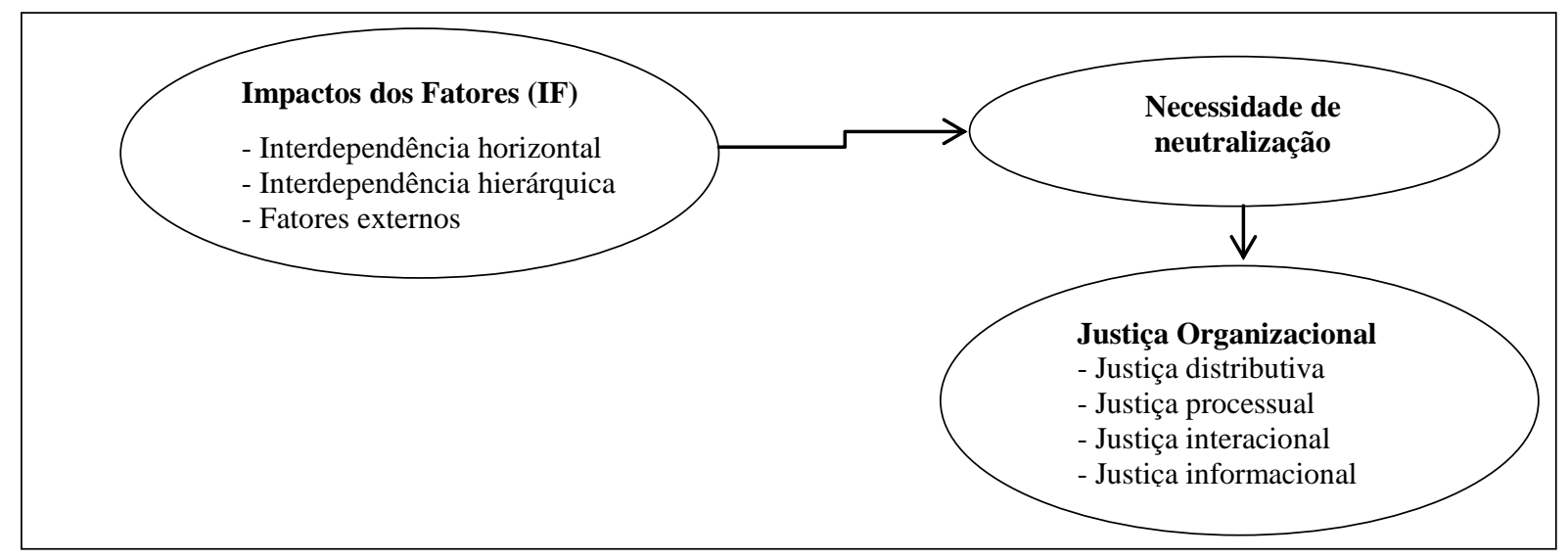

Figura 1 - Modelo conceitual

Fonte: Elaboração própria.

\subsection{Instrumento da pesquisa}

$\mathrm{O}$ instrumento de pesquisa, elaborado a partir das questões sobre controlabilidade analisadas no estudo de Giraud, Langevin e Mendoza (2008) e da leitura de material bibliográfico sobre justiça organizacional, foi constituído com 10 perguntas fechadas. $\mathrm{Na}$ 


\section{PERCEPÇÃO DOS GESTORES EM RELAÇÃO AO PRINCÍPIO DA CONTROLABILIDADE PARA O ALCANCE DA JUSTIÇA ORGANIZACIONAL}

aplicação do questionário junto aos gestores de unidades de negócios e de áreas funcionais das empresas pesquisadas, buscou-se a opinião dos gestores nos três tipos de fatores incontroláveis e sua percepção de justiça organizacional em quatro perspectivas. Os construtos e as questões do instrumento de pesquisa são apresentadas no Quadro 2.

Quadro 2 - Construtos e questões do instrumento de pesquisa

\begin{tabular}{|c|c|c|}
\hline Teoria & Construtos & Questões do instrumento de pesquisa \\
\hline \multirow{6}{*}{ 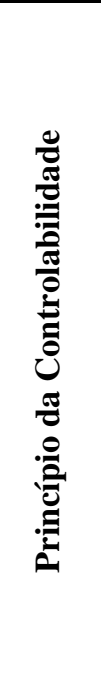 } & \multirow{2}{*}{$\begin{array}{l}\text { Interdependência } \\
\text { Horizontal } \\
\text { (IHO) }\end{array}$} & $\begin{array}{l}\text { 1) Até que ponto você estima que seus resultados tenham sido afetados pelas } \\
\text { decisões tomadas por outros gestores da sua empresa (interdependências horizontais } \\
\text { ou influência de gestores pertencentes ao mesmo nível hierárquico). (A1) }\end{array}$ \\
\hline & & $\begin{array}{l}\text { 4) Você considera que, na avaliação do seu desempenho, houve efeitos das decisões } \\
\text { tomadas por outros gestores da sua empresa (interdependências horizontais ou } \\
\text { influência dos gestores pertencentes ao mesmo nível hierárquico). (A2) }\end{array}$ \\
\hline & \multirow{2}{*}{$\begin{array}{l}\text { Interdependência } \\
\text { Hierárquica } \\
\text { (IHI) }\end{array}$} & $\begin{array}{l}\text { 2) Até que ponto você estima que seus resultados tenham sido influenciados pelas } \\
\text { decisões tomadas em níveis hierárquicos superiores (interdependências hierárquicas } \\
\text { ou influência de níveis hierárquicos superiores). (B1) }\end{array}$ \\
\hline & & $\begin{array}{l}\text { 5) Você considera que, na avaliação do seu desempenho, houve efeitos das decisões } \\
\text { tomadas em níveis hierárquicos superiores (interdependências hierárquicas). (B2) }\end{array}$ \\
\hline & \multirow{2}{*}{$\begin{array}{l}\text { Fatores Externos } \\
\qquad(\mathrm{FE})\end{array}$} & $\begin{array}{l}\text { 3) Até que ponto você estima que seus resultados tenham sido influenciados por } \\
\text { fatores externos à sua empresa (ambiente econômico e político, decisões de clientes } \\
\text { ou concorrentes e outros). (C1) }\end{array}$ \\
\hline & & $\begin{array}{l}\text { 6) Você considera que, na avaliação do seu desempenho, houve efeitos dos fatores } \\
\text { externos à sua empresa (ambiente econômico e político, decisões de clientes ou } \\
\text { concorrentes e outros). (C2) }\end{array}$ \\
\hline \multirow{4}{*}{ 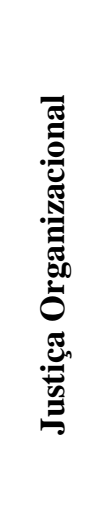 } & $\begin{array}{c}\text { Justiça } \\
\text { Distributiva (JD) }\end{array}$ & $\begin{array}{l}\text { 7) As recompensas (salários, benefícios, promoções) por mim recebidas são justas, } \\
\text { quando comparadas com o meu esforço empreendido para a realização das tarefas na } \\
\text { empresa e com as de outros indivíduos nas mesmas condições. (D1) }\end{array}$ \\
\hline & $\begin{array}{c}\text { Justiça } \\
\text { Processual (JP) }\end{array}$ & $\begin{array}{l}\text { 8) Considero justos os critérios e as condições inerentes ao processo decisório sobre } \\
\text { a definição e a alocação dos resultados na minha área de responsabilidade e as } \\
\text { recompensas pelas minhas contribuições para a empresa. (D2) }\end{array}$ \\
\hline & $\begin{array}{l}\text { Justiça } \\
\text { Interacional } \\
\text { (JINT) }\end{array}$ & $\begin{array}{l}\text { 9) A justiça interpessoal é fortemente percebida na minha empresa, particularmente } \\
\text { na forma como as pessoas são tratadas com cortesia e dignidade, e em especial o } \\
\text { respeito aos superiores hierárquicos ou pelas terceiras partes envolvidas na } \\
\text { realização de procedimentos nas áreas de responsabilidade. (D3) }\end{array}$ \\
\hline & $\begin{array}{l}\text { Justiça } \\
\text { Informacional } \\
\text { (JINF) }\end{array}$ & $\begin{array}{l}\text { 10) A justiça informacional é fortemente percebida na minha empresa, em especial } \\
\text { nas informações e explicações sobre as decisões tomadas, em termos de clareza, } \\
\text { oportunidade e abrangência na minha área de responsabilidade. (D4) }\end{array}$ \\
\hline
\end{tabular}
Fonte: Elaboração própria.

Em relação ao princípio da controlabilidade, para mensurar os impactos dos fatores incontroláveis sobre o desempenho dos gestores (A1, B1 e C1) utilizou-se uma escala tipo Likert de cinco pontos, em que $1=$ insignificante e $5=$ muito forte. No que tange à necessidade de neutralização dos fatores incontroláveis (A2, B2 e C2) utilizou-se uma escala de três pontos, em que 1 = atribuídos a sua área de responsabilidade, $2=$ parcialmente neutralizados e $3=$ totalmente neutralizados. No que compete à justiça organizacional (D1, D2, D3, D4), para mensurar a percepção dos gestores, utilizou-se uma escala de cinco pontos, em que $1=$ discordo totalmente e $5=$ concordo totalmente. 
O questionário foi elaborado no aplicativo Google Docs e enviado por correio eletrônico aos gestores das empresas pesquisadas, no período de maio a setembro de 2013. Com o instrumento de pesquisa procurou-se identificar a percepção de justiça organizacional a partir de cada um dos três fatores incontroláveis junto aos gestores que ocupam cargos de níveis hierárquicos semelhantes na organização.

\subsection{População e amostra}

A população do presente estudo compreendeu as "150 Melhores Empresas para Você Trabalhar", conforme a revista Você S/A do ano de 2011. A escolha da referida população deve-se ao fato do ranking ser composto de empresas que se destacam pelo índice de felicidade no trabalho relatado pelos funcionários que trabalham nas referidas empresas. $\mathrm{O}$ pressuposto é que nelas tenha um maior comprometimento organizacional e uma maior satisfação no trabalho, justificados pelas melhores práticas de gestão utilizadas (carreira, cidadania empresarial, desenvolvimento, estratégia e gestão, liderança e saúde no trabalho) a favor dos funcionários. A maioria das empresas que compõem a listagem oferece diferentes tipos de remuneração e benefícios, além da remuneração fixa.

O estudo focalizou empresas com sistemas de remuneração por recompensa e que adotam alguma forma de remuneração variável, sendo que o não cumprimento estabelecido no sistema de remuneração pode gerar insatisfação no trabalho e, por conseguinte, impactos negativos nos resultados da empresa. Da população inicial das 150 empresas, foram excluídas as seis empresas financeiras, em virtude das características específicas que a atividade possui comparativamente às demais atividades. Com as demais foi realizado contato telefônico para obter o endereço eletrônico dos gestores e para essas foi enviado o questionário. A amostra por acessibilidade compreendeu os gestores dessas empresas respondentes do questionário, totalizando 63 respostas validadas, de um total de 53 empresas.

\subsection{Procedimentos de análise dos dados}

Para fins de análise e tratamento estatístico descritivo, os dados foram emparelhados no programa MS Excel ${ }^{\mathrm{TM}}$ e transferidos ao Statistical Package for the Social Sciences - IBM SPSS®, Windows versão 20.0. Para testar as hipóteses foi utilizada a modelagem de Equações Estruturais (SEM). Segundo Hair Jr et al. (1998), entre as técnicas multivariadas de primeira geração, a SEM é a única que não tem como limitação de só examinar uma relação por vez, ao contrário disso, examina as variáveis dependentes em conjunto. Deste modo, utilizou-se a 
PERCEPÇÃO DOS GESTORES EM RELAÇÃO AO PRINCÍPIO DA

\section{CONTROLABILIDADE PARA O ALCANCE DA JUSTIÇA ORGANIZACIONAL}

técnica de Modelagem de Equações Estruturais (SEM), estimada a partir dos Mínimos Quadrados Parciais (Partial Least Squares - PLS).

Chin (1995) destaca que o PLS considera apenas a variação média extraída e o índice de R-quadrado $\left(\mathrm{R}^{2}\right)$ para avaliar o impacto dos construtos exógenos e endógenos, adequação das variáveis manifestas (indicadores) como medida de validação dos construtos. Portanto, essa técnica não oferece índices de ajuste global em relação aos modelos propostos e aos dados observados. O programa utilizado para o tratamento das variáveis e o teste de hipóteses foi o Smart PLS versão 2.0. Na metodologia empregada explicam-se aspectos inerentes, como: validade de convergência, confiabilidade composta do construto, índice de Bondade de Ajustamento (Goodness of Fit - GOF) e avaliação da significância de cada caminho (path).

A validade da convergência verifica a Variância Média Extraída ou Average Variance Extracted (AVE), que representa a quantidade de variância compartilhada entre os indicadores de cada um dos construtos ou variáveis latentes (HAIR JR et al., 1998). De acordo com Ferreira, Cabral e Saraiva (2010), a quantidade de AVE de um construto para avaliar a sua validade convergente deve ser maior do que 0,5 .

A validade discriminante também observa a AVE, e busca garantir que a inclusão de construtos de segunda ordem seja válida. O procedimento é realizado pela verificação se a raiz quadrada da AVE de cada uma das suas construções de primeiro nível é maior do que qualquer das correlações entre esta construção de primeiro nível e as demais, como foi observado por Fornell e Larcker (1981). Em seguida, efetua-se o teste de Confiabilidade Composta do Construto. Para Chin (1995), a confiabilidade composta de cada construto deve exceder o valor de 0,70 para assegurar a adequação na estimativa do PLS.

O índice de Bondade de Ajustamento (Goodness of Fit - GoF) foi proposto por Tenenhaus, Chatelin e Lauro (2005), para medir o desempenho global do modelo a partir do cálculo da média geométrica entre a média do $\mathrm{R}^{2}$ e a média da AVE dos construtos. Como recomendado por Wetzels, Odekerken-Schröder e Van Oppen (2009), o índice GoF deve assumir valores acima de 0,36 para o desenvolvimento de pesquisas no âmbito das ciências sociais e comportamentais.

Para avaliar a significância de cada caminho (path) dos coeficientes ou a influência de um construto em detrimento de outro, utilizou-se um procedimento disponível no SmartPLS denominado de Bootstrapping. Para Ringle, Wende e Will (2006), o Bootstrapping é definido como uma forma de subamostra, em que os dados originais são repetidamente amostrados para substituição no modelo de estimativa. As estimativas dos parâmetros e erros padrão não 
Ilse Maria Beuren, Hugo Dias Amaro \& Pedro Ylunga Costa da Silva

são calculados com pressupostos estatísticos, em vez disso, são baseados em observações empíricas (HAIR JR et al., 1998).

As amostras do bootstrapping são do mesmo tamanho da amostra original e recomenda-se que o número de subamostras exceda 100, de preferência superior a 200, podendo ainda ser maior (TENENHAUS; CHATELIN; LAURO, 2005; HAIR JR et al., 1998). Nessa pesquisa, a amostra original foi de $n=63$ e, conforme recomendado por Hair $\mathrm{Jr}$ et al. (1998), o número de subamostras adotado foi $\mathrm{N}=2000$.

\section{DESCRIÇÃO E ANÁLISE DOS RESULTADOS}

Nesta seção apresentam-se os dados demográficos, a validade e a confiabilidade dos construtos, o modelo estrutural e seus resultados.

\subsection{Dados demográficos}

Na Tabela 1 apresentam-se os dados demográficos dos respondentes da pesquisa.

Tabela1 - Perfil dos respondentes da pesquisa

\begin{tabular}{|c|c|c|c|c|c|c|c|c|c|}
\hline \multicolumn{2}{|c|}{ Variáveis demográficas } & \multirow{2}{*}{$\begin{array}{c}\text { Universo } \\
\mathbf{Q t} \\
45\end{array}$} & \multicolumn{2}{|c|}{ Amostra } & \multicolumn{2}{|c|}{ Variáveis demográficas } & \multirow{2}{*}{$\begin{array}{c}\text { Universo } \\
\mathbf{Q t} \\
6\end{array}$} & \multicolumn{2}{|c|}{ Amostra } \\
\hline \multirow{3}{*}{ Gênero } & Masculino & & $\frac{\mathbf{Q t}}{45}$ & $\begin{array}{l}\% \\
71\end{array}$ & \multirow{2}{*}{$\begin{array}{l}\text { Grau de } \\
\text { escolaridade }\end{array}$} & Segl & & $\frac{\mathbf{Q t}}{6}$ & $\begin{array}{c}\% \\
10\end{array}$ \\
\hline & Feminino & 18 & 18 & 29 & & Superior & 13 & 13 & 21 \\
\hline & Missing values & 0 & 0 & 0 & & Especialização & 31 & 31 & 49 \\
\hline \multirow{8}{*}{$\begin{array}{l}\text { Faixa } \\
\text { etária }\end{array}$} & Até 25 anos & 2 & 2 & 3 & & Mestrado & 12 & 12 & 19 \\
\hline & 26 a 30 anos & 11 & 11 & 17 & & Doutorado & 1 & 1 & 2 \\
\hline & 31 a 35 anos & 19 & 19 & 30 & & Missing values & 0 & 0 & 0 \\
\hline & 36 a 40 anos & 14 & 14 & 22 & \multirow{5}{*}{$\begin{array}{ll}\text { Tempo de } \\
\text { empresa }\end{array}$} & De 1 até 5 anos & 41 & 41 & 65 \\
\hline & 41 a 45 anos & 8 & 8 & 13 & & De 5 até 6 anos & 8 & 8 & 13 \\
\hline & 46 a 50 anos & 4 & 4 & 6 & & De 6 até 9 anos & 9 & 9 & 14 \\
\hline & 51 anos ou mais & 5 & 5 & 8 & & Mais de 10 anos & 13 & 13 & 21 \\
\hline & Missing values & 0 & 0 & 0 & & Missing values & 0 & 0 & 0 \\
\hline
\end{tabular}

Fonte: Elaboração própria.

Constata-se nos dados demográficos da Tabela 1 que, 71,43\% dos respondentes são do gênero masculino (45 respondentes), a maioria pertence à faixa etária de 31 a 35 anos (30\%) e $65 \%$ indicou como tempo de empresas a faixa de 1 a 5 anos. Observa-se ainda que $49 \%$ dos respondentes possuem pós-graduação lato sensu. Esses dados demográficos sinalizam que os respondentes apresentam condições de responder o instrumento de pesquisa.

\subsection{Modelagem de Equações Estruturais}

Com base no modelo conceitual teórico proposto, realizou-se a análise dos dados coletados, utilizando a técnica de estimação de covariância de SEM-PLS, conforme Figura 2. 
PERCEPÇÃO DOS GESTORES EM RELAÇÃO AO PRINCÍPIO DA CONTROLABILIDADE PARA O ALCANCE DA JUSTIÇA ORGANIZACIONAL

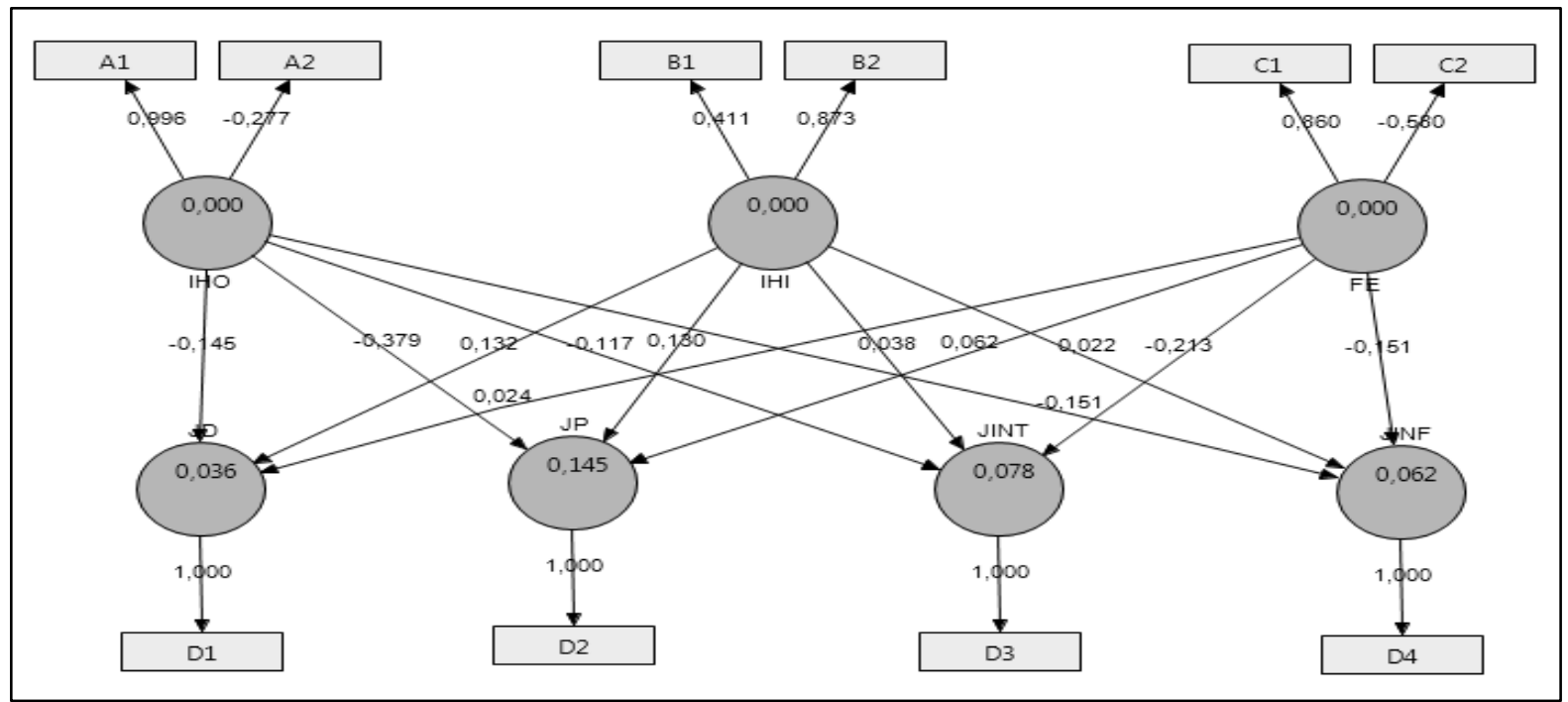

Figura 2 - Modelo proposto com valores de $\mathrm{R}^{2}$ Fonte: Elaboração própria.

\subsection{Testes de validação e adequação de modelo SEM-PLS}

A análise do modelo proposto com valores $\mathrm{R}^{2}$ precede das análises de relações entre os construtos, com procedimentos e critérios definidos pela técnica de estimação de covariância de SEM-PLS, em específico, a validade de convergência, a validade discriminante e o índice de Bondade de Ajustamento (Goodness of Fit - GOF).

Na Tabela 2 ilustra-se a validade convergente (AVE) do modelo, que indica o grau em que os indicadores de um fator, que teoricamente são altamente relacionados, se correlacionam.

Tabela 2 - Índices de adequação de modelo

\begin{tabular}{|c|c|c|c|c|c|}
\hline & $\begin{array}{c}\text { Variância } \\
\text { Média } \\
\text { Extraída }\end{array}$ & $\begin{array}{c}\text { Confiabilidade } \\
\text { Composta }\end{array}$ & R-Quadrado & Comunalidade & Redundância \\
\hline IHO & 0,534 & 0,356 & 0,000 & 0,534 & 0,000 \\
\hline IHI & 0,466 & 0,607 & 0,000 & 0,466 & 0,000 \\
\hline FE & 0,538 & 0,078 & 0,000 & 0,538 & 0,000 \\
\hline JD & 1,000 & 1,000 & 0,036 & 1,000 & $-0,002$ \\
\hline JP & 1,000 & 1,000 & 0,145 & 1,000 & $-0,013$ \\
\hline JINT & 1,000 & 1,000 & 0,078 & 1,000 & 0,063 \\
\hline JINF & 1,000 & 1,000 & 0,062 & 1,000 & 0,039 \\
\hline
\end{tabular}

Observa-se na Tabela 2, que somente foi identificado um indicador de Variância Média Extraída (Average Variance Extracted - AVE) com valor inferior a 0,5 (IHI = 0,466). De forma geral, dentro desse teste o modelo é aceito. No que tange aos resultados dos coeficientes de Confiabilidade Composta (Composite Reliability - CR), os construtos FE $(0,078)$, IHO $(0,356)$ e IHI $(0,607)$ estão abaixo do mínimo recomendado de 0,70 , o que representa $19,0 \%$ da variância, considerado o tamanho da amostra. Portanto, esses valores não

REAd | Porto Alegre - Edição 81 - N 2 - maio/agosto 2015 - p. 378-405 
Ilse Maria Beuren, Hugo Dias Amaro \& Pedro Ylunga Costa da Silva

são significativos a um nível de significância 0,05 , conforme prescrito por Hair Jr et al. (1998) e Tenenhaus, Chatelin e Lauro (2005).

Na Tabela 3 evidenciam-se os índices do teste de validade discriminante do modelo.

Tabela 3 - Índices de adequação do modelo

\begin{tabular}{|c|c|c|c|c|c|c|c|}
\hline Construtos & FE & \multicolumn{1}{c}{ IHI } & \multicolumn{1}{c}{ IHO } & JD & \multicolumn{1}{l}{ JINF } & JINT & JP \\
\hline FE & 1,000 & & & & & & \\
\hline IHI & $\mathbf{0 , 0 7 9}$ & 1,000 & & & & & \\
\hline IHO & $\mathbf{0 , 3 7 5}$ & $\mathbf{0 , 0 2 8}$ & 1,000 & & & & \\
\hline JD & $\mathbf{- 0 , 0 2 0}$ & $\mathbf{0 , 1 3 0}$ & $\mathbf{- 0 , 1 3 2}$ & 1,000 & & & \\
\hline JINF & $\mathbf{- 0 , 2 0 6}$ & $\mathbf{0 , 0 0 6}$ & $\mathbf{- 0 , 2 0 7}$ & $\mathbf{0 , 3 2 7}$ & 1,000 & & 1,000 \\
\hline JINT & $\mathbf{- 0 , 2 5 4}$ & $\mathbf{0 , 0 1 8}$ & $\mathbf{- 0 , 1 9 6}$ & $\mathbf{0 , 2 9 4}$ & $\mathbf{0 , 6 3 1}$ & 1,000 & \\
\hline JP & $\mathbf{- 0 , 0 7 0}$ & $\mathbf{0 , 1 2 4}$ & $\mathbf{- 0 , 3 5 2}$ & $\mathbf{0 , 5 7 7}$ & $\mathbf{0 , 4 9 2}$ & $\mathbf{0 , 5 2 4}$ & \\
\hline
\end{tabular}

Verifica-se na Tabela 3, que não há correlação entre os construtos de primeira ordem, que excedem em magnitude a raiz quadrada do AVE dos construtos relacionados, portanto, garantem a validade discriminante. Segundo Hair Jr et al. (1998), as correlações entre as variáveis devem ser inferiores a 0,95 para evitar índices de colinearidade. Nesse estudo, nenhuma das correlações é superior a 0,95.

Em resgate aos dados da Tabela 2, somente o construto IHI não excede o mínimo recomendado de 0,5 , demonstrando a qualidade dos construtos, o que resulta em validade discriminante adequada.

No que concerne ao índice de Bondade de Ajustamento (Goodness of Fit - GoF), proposto por Tenenhaus, Chatelin e Lauro (2005), no presente estudo esse teste atingiu o valor calculado de 0,1895, que está abaixo do mínimo de 0,36 recomendado por Wetzels, Odekerken-Schröder e Van Oppen (2009). Isso sugere que o desempenho global do modelo, a partir do cálculo da média geométrica entre a média do $\mathrm{R}^{2}$ e a média da AVE dos construtos, não está totalmente adequado. Todavia, como a validade convergente e a validade discriminante se apresentaram adequadas, procedeu-se à análise das relações ou caminhos (path).

\subsection{Análise das relações ou caminhos (path)}

Na Tabela 4 mostram-se os principais resultados dos efeitos totais observados por Park (2009). Para a avaliação da magnitude e importância dos coeficientes de caminho, efetuou-se a análise de bootstrapping, gerando $\mathrm{N}=2000$ subamostras diferentes, cada uma com $\mathrm{n}=63$ observações, como recomendado pela literatura (HAIR JR et al., 1998). 
PERCEPÇÃO DOS GESTORES EM RELAÇÃO AO PRINCÍPIO DA CONTROLABILIDADE PARA O ALCANCE DA JUSTIÇA ORGANIZACIONAL

Tabela 4 - Efeitos diretos, totais e resultado das hipóteses entre os construtos

\begin{tabular}{l|c|c|c|c|c|c}
\hline \multirow{2}{*}{\multicolumn{1}{c|}{ Relações (path) }} & \multicolumn{3}{|c|}{ Direto } & \multicolumn{3}{c}{ Total } \\
\cline { 2 - 7 } & Valor & t-valor & p-valor & Valor & t-valor & p-valor \\
\hline (H1) IHO -> JD (H1a) & $-0,145$ & 0,942 & 0,346 & $-0,145$ & 0,942 & 0,346 \\
\hline (H1) IHO -> JP (H1b) & $-0,379$ & 2,071 & $\mathbf{0 , 0 3 8}$ & $-0,379$ & 2,071 & 0,038 \\
\hline (H1) IHO -> JINT (H1c) & $-0,117$ & 0,768 & 0,443 & $-0,117$ & 0,768 & 0,443 \\
\hline (H1) IHO -> JINF (H1d) & $-0,151$ & 0,983 & 0,326 & $-0,151$ & 0,983 & 0,326 \\
\hline (H2) IHI -> JD (H2a) & 0,132 & 0,787 & 0,431 & 0,132 & 0,787 & 0,431 \\
\hline (H2) IHI -> JP (H2b) & 0,130 & 0,824 & 0,410 & 0,130 & 0,824 & 0,410 \\
\hline (H2) IHI -> JINT (H2c) & 0,039 & 0,171 & 0,864 & 0,039 & 0,171 & 0,864 \\
\hline (H2) IHI -> JINF (H2d) & 0,022 & 0,140 & 0,888 & 0,022 & 0,140 & 0,888 \\
\hline (H3) FE -> JD (H3a) & 0,024 & 0,147 & 0,883 & 0,024 & 0,147 & 0,883 \\
\hline (H3) FE -> JP (H3b) & 0,062 & 0,443 & 0,658 & 0,062 & 0,443 & 0,658 \\
\hline (H3) FE -> JINT (H3c) & $-0,213$ & 0,750 & 0,453 & $-0,213$ & 0,750 & 0,453 \\
\hline (H3) FE -> JINF (H3d) & $-0,151$ & 0,679 & 0,497 & $-0,151$ & 0,679 & 0,497 \\
\hline
\end{tabular}

* significante $\mathrm{p}<0,05$

Fonte: Elaboração própria.

Os resultados da Tabela 4 permitem analisar as hipóteses elaboradas nessa pesquisa. No que concerne à hipótese $\mathrm{H} 1 \mathrm{~b}$ - A extensão em que o desempenho dos gestores é afetado por decisões tomadas por gestores do mesmo nível hierárquico está positivamente relacionada ao desejo dos gestores de que os efeitos dessas decisões sejam neutralizados em sua avaliação de desempenho, aumentando a percepção da justiça processual - esta não foi rejeitada ao nível de $\mathrm{p}<0,05$. As demais hipóteses não apresentaram significância estatística ao nível de p<0,05.

Fazendo-se um comparativo com os resultados da pesquisa de Giraud, Langevin e Mendoza (2008), esses encontraram uma relação positiva entre o grau do impacto dos fatores incontroláveis internos e o desejo de neutralização na avaliação de desempenho dos gestores. No presente estudo confirma-se isso apenas na hipótese H1b, que aponta haver significância estatística entre o desejo de neutralização dos fatores internos e no que compete às decisões de outros gestores do mesmo nível hierárquico, sendo que essa neutralização leva a um aumento da percepção de justiça processual.

O resultado do presente estudo coaduna também parcialmente com os achados de Vancil (1979), com exceção da hipótese H1b, o qual constatou que os gerentes de centros de lucro consideram injusto serem avaliados com base em resultados afetados por fatores incontroláveis de origem interna, como interdependências estruturais e incorporação de preços de transferência de outros departamentos. Especula-se que as divergências nos resultados dessa pesquisa podem estar associadas com o observado por Merchant (1989), que quanto mais são incontroláveis os fatores, maior será o efeito destes sobre o desempenho dos gestores, o que resulta no aumento do desejo dos gestores para a sua neutralização.

O estudo de Giraud, Langevin e Mendoza (2008) aponta ainda que não há correlação entre o grau do impacto dos fatores incontroláveis externos e o desejo de neutralização na REAd | Porto Alegre - Edição 81 - N² 2 - maio/agosto 2015 - p. 378-405 
avaliação de desempenho dos gestores. Do mesmo modo, nessa pesquisa não se constatou correlação com os fatores externos considerados. Uma possível justificativa apresentada pelos autores para a não relação é que os gestores temem que um nível elevado de dificuldade de neutralizar o seu efeito poderia resultar em subjetividade na avaliação de desempenho e assim resultar em injustiça nas diferentes dimensões da justiça organizacional.

\section{CONSIDERAÇÕES FINAIS}

Este estudo averiguou a percepção dos gestores em relação ao princípio da controlabilidade para o alcance da justiça organizacional. De acordo com o princípio da controlabilidade, os gestores só podem ser avaliados pelos fatores controláveis e a neutralização dos fatores incontroláveis em sua avaliação de desempenho leva à percepção de justiça organizacional. De modo geral, as análises do estudo mostram que o efeito da aplicação do princípio da controlabilidade sobre o desempenho dos gestores nas empresas pesquisadas não é direta e que não leva a um aumento da percepção de justiça organizacional.

Pautadas no objetivo do estudo três hipóteses foram testadas. Inicialmente testou-se a H1 - a extensão em que o desempenho dos gestores é afetado por decisões tomadas por gestores do mesmo nível hierárquico está positivamente relacionada ao desejo dos gestores de que os efeitos dessas decisões sejam neutralizados em sua avaliação de desempenho, aumentando a percepção da justiça distributiva (H1a), justiça processual (H1b), justiça interacional (H1c) e justiça informacional (H1d). Somente a hipótese H1b foi confirmada (pvalor de $0,038^{*}$ ), sendo que as demais foram rejeitadas a uma significância de $\mathrm{p}<0,05$.

A H2 prevê que a extensão em que o desempenho dos gestores é afetado pelas decisões tomadas por seus superiores hierárquicos é positivamente relacionada ao desejo dos gestores de que os efeitos dessas decisões sejam neutralizados em sua avaliação de desempenho, aumentando a percepção da justiça distributiva (H2a), justiça processual (H2b), justiça interacional (H2c) e justiça informacional (H2d). O modelo proposto de estimação de covariância de SEM-PLS para confirmar essa hipótese não apresentou significância estatística para nenhuma relação estudada.

A H3 prevê que a extensão em que o desempenho dos gestores é afetado por fatores externos incontroláveis está positivamente relacionada com o desejo dos gestores de que os efeitos de tais fatores sejam neutralizados em sua avaliação de desempenho, aumentando a percepção da justiça distributiva (H3a), justiça processual (H3b), justiça interacional $(\mathrm{H} 3 \mathrm{c})$ e justiça informacional (H3d). Esta hipótese, com base na metodologia de análise do modelo 


\section{PERCEPÇÃO DOS GESTORES EM RELAÇÃO AO PRINCÍPIO DA CONTROLABILIDADE PARA O ALCANCE DA JUSTIÇA ORGANIZACIONAL}

proposto, também não apresentou significância estatística.

Conclui-se que entre os gestores pesquisados parece não haver uma preocupação com a neutralização dos fatores incontroláveis. Talvez possa haver o desejo da não neutralização dos fatores incontroláveis, tendo como pressuposto a ideia explicitada por Frow, Marginson e Ogden (2005) e Giraud, Langevin, Mendoza (2008), de que os gestores esperam obter benefícios financeiros com os fatores que não controlam. No entanto, os resultados desta pesquisa limitam-se à opinião da amostra pesquisada. Além disso, o formato das questões pode ter ocasionado um viés nas respostas, interferindo nos resultados da pesquisa.

Assim, recomenda-se a replicação deste estudo em uma amostra maior de gestores e com ajustes julgados relevantes nas métricas do instrumento de pesquisa. Apesar das limitações apontadas, este estudo estende o conhecimento sobre o tema ao investigar a compreensão dos gestores no que diz respeito ao princípio da controlabilidade. $O$ desenvolvimento mais sistemático e a aplicação do instrumento para públicos distintos pode constituir-se em interessante campo de pesquisa com vistas à aumentar as evidências empíricas relativas ao princípio da controlabilidade em organizações.

\section{REFERÊNCIAS}

AGUIAR, A. B.; TEIXEIRA, A. J. C.; NOSSA, V.; GONZAGA, R. P. Associação entre sistema de incentivos gerenciais e práticas de contabilidade gerencial. RAE. Revista de Administração de Empresas, v. 52, n. 1, p. 40-54, 2012.

ANGONESE, R.; BEUREN, I. M. Percepção de alunos de cursos de pós-graduação sobre a aplicação do princípio da controlabilidade. In: SEMEAD, 15., 2012, São Paulo. Anais... São Paulo: FEA/USP, 2012.

ANTLE, R.; DEMSKI, J. S. The controllability principle in responsibility accounting. The Accounting Review, v. 63, n. 4, p. 700-718, 1988.

ASSMAR, E. M. L.; FERREIRA, M. C.; SOUTO, S. O. Justiça organizacional: uma revisão crítica da literatura. Psicologia: Reflexão e Crítica, v. 18, n. 3, p. 443-453, 2005.

BABCOCK, L.; LOEWENSTEIN, G.; ISSACHAROFF, S.; CAMERER, C. Biased judgments of fairness in bargaining. American Economic Review, v. 85, n. 5, p. 1337-1343, 1995.

BALDWIN, S. Organizational justice. Falmer, Brighton, UK: Institute for Employments REAd | Porto Alegre - Edição 81 - N² 2 - maio/agosto 2015 - p. 378-405 
Studies (IES), University of Sussex Campus, 2006.

BEUREN, I. M.; SANTOS, V. Percepção de justiça organizacional na avaliação de desempenho de controllers. Enfoque: Reflexão Contábil, v. 31, n. 3, p. 53-72, 2012.

BIES, R. J.; MOAG, J. S. Interactional justice: communication criteria of fairness. Research on Negotiation in Organizations, v. 1, n. 1, p. 43-55, 1986.

BIES, R. J.; SHAPIRO, D. L. Interactional fairness judgments: The influence of causal accounts. Social Justice Research, v. 1, n. 2, p. 199-218, 1987.

BURKERT, M.; FISCHER, F. M.; SCHAFFER, U. Application of the controllability principle and managerial performance: The role of role perceptions. Management Accounting Research, v. 22, n. 3, p. 143-159, 2011.

BURNEY, L. L.; HENLE, C. A.; WIDENER, S. K. A path model examining the relations among strategic performance measurement system characteristics, organizational justice, and extra-and in-role performance. Accounting, Organizations and Society, v. 34, n. 3, p. 305-321, 2009.

CAMARGOS, M. A.; HELAL, D. H.; BOAS, A. P. Análise empírica da relação entre a remuneração de executivos e o desempenho financeiro de empresas brasileiras. In: ENEGEP, 27., 2007, Foz do Iguaçu. Anais... Rio de Janeiro: ABEPRO, 2007.

CHIN, W. W. Partial least squares is to LISREL as principal components analysis is to common factor analysis. Technology Studies, v. 2, n. 2, p. 315-319, 1995.

CHOUDHURY, N. Responsibility accounting and controllability. Accounting and Business Research, v. 16, n. 63, p.189-198, 1986.

COLQUITT, J. A.; CONLON, D. E.; WESSON, M. J.; PORTER, C. O.; NG, K. Y. Justice at the millennium: a meta-analytic review of 25 years of organizational justice research. Journal of Applied Psychology, v. 86, n. 3, p. 425-445, 2001.

DALMACIO, F. Z.; REZENDE, A. J.; SLOMSKI, V. Análise setorial das medidas de performance utilizadas nos contratos de remuneração dos gestores. Revista Universo Contábil, v. 5, n. 3, p. 06-23, 2009.

DEMO, P. Metodologia científica em Ciências Sociais. 2. ed. São Paulo: Atlas, 1989. 


\section{PERCEPÇÃO DOS GESTORES EM RELAÇÃO AO PRINCÍPIO DA CONTROLABILIDADE PARA O ALCANCE DA JUSTIÇA ORGANIZACIONAL}

DEMSKI, J. S. Uncertainty and evaluation based on controllable performance. Journal of Accounting Research, v. 14, n. 2, p. 230-245, 1976.

FERREIRA, P.; CABRAL, I.; SARAIVA, J. An integrated framework based on the ECSI approach to link mould customers' satisfaction and product design. Total Quality Management and Business Excellence, v. 21, n. 12, p. 1383-1401, 2010.

FILENGA, D.; SIQUEIRA, M. M. M. O impacto de percepções de justiça em três bases de comprometimento organizacional. Revista de Administração (FEA/USP), v. 41, n. 4, p. 431441, 2006.

FOGARTY, T. J.; SINGH, J.; RHOADS, G. K.; MOORE, R. K. Antecedents and consequences of burnout in accounting: beyond the role stress model. Behavioral Research in Accounting, v. 12, n. 1, p. 31-67, 2000.

FOLGER,R.; CROPANZANO, R. Organizational justice and human resource management. Thousand Oaks, CA: Sage. 1998.

FORNELL, C.; LARCKER, D. F. Evaluating structural equation models with unobservable variables and measurement error. Journal of Marketing Research, v. 18, n. 1, p. 39-50, 1981.

FROW, N.; MARGINSON, D.; OGDEN, S. Encouraging strategic behavior while maintaining management control: multi-functional project teams, budgets, and the negotiation of shared accountabilities in contemporary enterprises. Management Accounting Research, v. 16, n. 3, p. 269-292, 2005.

GIL, A. C. Como elaborar projetos de pesquisa. 4. ed. São Paulo: Atlas, 2002.

GIRAUD, F.; LANGEVIN, P.; MENDOZA, C. Justice as a rationale for the controllability principle: A study of managers opinions. Management Accounting Research, v. 19, n. 1, p. 32-44, 2008.

GHOSH, D. Alternative measures of managers' performance, controllability, and the outcome effect. Behavioral Research in Accounting, v. 17, n. 1, p. 55-70, 2005.

GHOSH, D.; LUSCH, R. F. Outcome effect, controllability and performance evaluation of managers: some field evidence from multi-outlet businesses. Accounting, Organizations and Society, v. 25, n. 1, p. 411-425, 2000. 
Ilse Maria Beuren, Hugo Dias Amaro \& Pedro Ylunga Costa da Silva

GREENBERG, J. Reactions to procedural injustice in payment distributions: Do the means justify the ends? Journal of Applied Psychology, v. 72, n. 1, p. 55-61, 1987.

GREENBERG, J. Organizational justice: yesterday, today and tomorrow. Journal Manage, v. 16, n. 2, p. 399-432, 1990.

GREENBERG, J. The intellectual adolescence of organizational justice: you've come a long way, maybe. Social Justice Research, v. 6, n. 1, p. 135-148, 1993.

HAIR JR., J. F.; ANDERSON, R. E.; TATHAM, R. L.; BLACK, W. C. Multivariate data analysis. 5. ed. New Jersey: Prentice Hall, 1998.

HARTMANN, F; SLAPNICAR, S. How formal performance evaluation affects trust between superior and subordinate managers. Accounting, Organizations and Society, v. 34, n. 1, p.722737, 2009.

HIRST, M. The controllability of financial outcomes. Abacus, v. 19, n. 1, p. 29-38, 1983.

HUFFMAN, C.; CAIN, L. B. Effects of considering uncontrollable factors in sales force performance evaluation. Psychology \& Marketing, v. 17, n. 9, p. 799-833, 2000.

JAWAHAR, I. M. A model of organizational justice and workplace aggression. Journal of Management, v. 28, n. 6, p. 811-834, 2002.

KONOVSKY, M. A.; CROPANZANO, R. Perceived fairness of employee drug testing as a predictor of employee attitudes and job performance. Journal of Applied Psychology, v. 76, n. 5, p. 698, 1991.

LANGEVIN, P.; MENDOZA, C. How can management control system fairness reduce managers' unethical behaviours? European Management Journal, v. 31, n. 3, p. 209-222, 2013.

LIBBY, T. The influence of voice and explanation on performance in a participative budgeting setting. Accounting, Organizations and Society, v. 24, n. 1, p.125-137, 1999.

MANZONI, J. F. Management control: toward a new paradigm? In: EPSTEIN, M. J.; MANZONI, J. F. (ed.). Performance measurement and management control. Oxford: JAI Press, 2002, p.15-46.

MARTINS, G. A.; THEÓPHILO, C. R. Metodologia da investigação científica para ciências REAd | Porto Alegre - Edição 81 - N² 2 - maio/agosto 2015 - p. 378-405 
PERCEPÇÃO DOS GESTORES EM RELAÇÃO AO PRINCÍPIO DA CONTROLABILIDADE PARA O ALCANCE DA JUSTIÇA ORGANIZACIONAL

sociais aplicadas. 2. ed. São Paulo: Atlas, 2009.

MERCHANT, K. Rewarding results: motivating profit center managers. Boston: Harvard Business School Press, 1989.

MERCHANT, K. A.; MANZONI, J. F. The achievability of budget targets in profit centers: a field study. The Accounting Review, v. 64, n. 3, p. 539-558, 1989.

MERCHANT, K. A.; VAN DER STEDE, W. A. Management control systems: performance measurement, evaluation and incentives. Boston: Prentice Hall, 2003.

MODELL, S.; LEE, A. Decentralization and reliance on the controllability principle in the public sector. Financial Accountability \& Management, v. 17, n. 3, p. 191-218, 2001.

NADIRI, H.; TANOVA, C. An investigation of the role of justice in turnover intentions, job satisfaction, and organizational citizenship behavior in hospitality industry. International Journal of Hospitality Management, v. 29, n. 1, p. 33-41, 2010.

OCANSEY, E. O.; ENAHORO, J. A. Determinant controllability of responsibility accounting in profit planning. Canadian Social Science, v. 8, n. 6, p. 91-95, 2012.

PARK, S. Y. An analysis of the technology acceptance model in understanding university students' behavioral intention to use e-learning. Journal of Educational Technology \& Society, v.12, n. 3, p. 150-162, 2009.

PARKER, R. J.; KOHLMEYER III, J. M. Organizational justice and turnover in public accounting firms: a research note. Accounting, Organizations and Society, v. 30, n. 1, p. 357$369,2005$.

PEREIRA, J. B. C. A Relação entre as dimensões de justiça organizacional e as atitudes dos indivíduos diante da diversidade. 2008. 329f. Tese (Doutorado em Administração de Empresas) - Universidade Presbiteriana Mackenzie, São Paulo, 2008.

REGO, A.; SOUTO, S. A percepção de justiça como antecedente do comprometimento organizacional: um estudo luso-brasileiro. RAC. Revista de Administração Contemporânea, v. 8, n. 1, p. 151-177, 2004.

RINGLE, C. M.; WENDE, S.; WILL, S. SmartPLS 2.0 (M3) Beta. Hamburg: University of Hamburg, 2005. 
SEIFERT, D. L.; SWEENEY, J. T.; JOIREMAN, J.; THORNTON, J. M. The influence of organizational justice on accountant whistleblowing. Accounting, Organizations and Society, v. 35, n. 7, p. 707-717, 2010.

SHIH, M. S. H. Responsibility accounting and controllability: Determinants of performance evaluation systems for plant managers in Canada. Social Science Research Network, 1997. Disponível em: <http://papers.ssrn.com/sol3/papers.cfm?abstract_id=42131>. Acesso em: 31 out. 2013.

SOTOMAYOR, A. M. S. B. As percepções de justiça organizacional na avaliação de desempenho: consequências sobre o compromisso organizacional e o compromisso face ao superior hierárquico. 2006. 453 f. Tese (Doutorado em Gestão) - Instituto Superior de Economia e Gestão, Universidade Técnica de Lisboa, Lisboa, 2006.

SOTOMAYOR, A. M. S. B. Avaliação de desempenho e compromisso organizacional: a perspectiva da justiça organizacional. Revista Universo Contábil, v. 3, n. 3, p. 87-100, 2007.

SOUSA, I. A. C.; MENDONÇA, H. Justiça organizacional, prazer e sofrimento no trabalho: análise de um modelo mediacional. RAM. Revista de Administração Mackenzie, v. 10, n. 4, p. 57-74, 2009.

TEIXEIRA, A. J. C.; GONZAGA, R. P.; SANTOS, A. V. S. M. A utilização de ferramentas de contabilidade gerencial nas empresas do Estado do Espírito Santo. Brazilian Business Review, v. 8, n. 3, p.108-127, 2011.

TENENHAUS, M.; CHATELIN, Y. M.; LAURO, C. PLS path modeling. Computational Statistics \& Data Analysis, v. 48, n. 1, p. 159-205, 2005.

VANCIL, R. F. Decentralization: ambiguity by design. Homewood, Illinois: Irwin, 1979.

WETZELS, M.; ODEKERKEN-SCHRODER, G.; VAN OPPEN, C. Using PLS path modeling for assessing hierarchical construct models: guidelines and empirical illustration. MIS Quarterly, v. 33, n. 1, p. 177-195, 2009.

ZAINALIPOUR, H.; FINI, A. A. S.; MIRKAMALI, S. M. A study of relationship between organizational justice and job satisfaction among teachers in Bandar Abbas middle school. Procedia - Social and Behavioral Sciences, v. 5, n. 1, p. 1986-1990, 2010. 